\title{
Effect of Eimeria stiedae infestation on the immune response of rabbit vaccinated with oil adjuvant polyvalent rabbit Pasteurellosis
}

\author{
M. S. El-Nabarawy*, Elham. A. Youssef, N. B. Eskander, Lilian. F. S. Melika, \\ Amina A. El-Bayoumy
}

Veterinary Serum and Vaccine Research Institute, Abbasia, Cairo, Egypt.

\begin{abstract}
In an attempt to evaluate the possible role of Eimeria stiedae infection on rabbit vaccinated with haemorrhagic septicaemia oil adjuvant vaccine, a total of 60 New-Zealand rabbits were divided into 6 groups (A- F). The first four groups subdivided into two subgroups. The subgroups $(A 1, A 2)$ vaccinated and infected at time of $1^{\text {st }}$ dose of vaccine, subgroup (B1, B2) vaccinated and infected at 2 weeks post $1^{\text {st }}$ vaccination, subgroup $(\mathrm{C} 1, \mathrm{C} 2)$ which vaccinated and infected at the time of $2^{\text {nd }}$ dose of vaccination, finally subgroup $(D 1, D 2)$ vaccinated and infected at 2 weeks post $2^{\text {nd }}$ dose of vaccine. Group $E$ vaccinated only but the group $F$ left as non vaccinated non infected (control). The results revealed that $E$. stiedae infection at the time or after 2 weeks from first or second dose of vaccination (A1, B1, C1 and D1) and treated with semduramycine 150 showed slight decrease of the antibody titer in contrast the untreated group (A2, B2, C2 and D2) showed sudden decrease of $P$. multocida antibody titer measured by indirect haemagglutination and ELISA test. Vaccinated group (E) was the superior one showing the highest antibody titer. The challenge test of all rabbit groups with virulent $P$. multocida revealed a protective percent of $83.4 \%, 50 \%, 100 \%$ and $0 \%$ in treated, untreated, vaccinated and control group respectively, but subgroups C2, D2 the protective value was $33.4 \%$ this due to challenge concurrency post or at the time of infection. These findings reflect the important to avoid coccidial infection following vaccination programs to obtain better immune response to haemorrhagic septicaemia oil adjuvant pasteurellosis vaccine and high level of protection.
\end{abstract}

Many countries of the world including Egypt, rabbits represent as a good and acceptable source of animal protein and in addition to the fact that rabbit, breed mostly in large numbers and their offspring grow rapidly. Moreover, its skin has also an economic value for production, in addition it is one of the most important experimental animals (Sandford, 1986).

Rabbit meat as food is pearly white, poor in fat, high nutritious, easily digestible, and palatable, for these reasons rabbit meat is recommended for sick and convalescent people.

Any disease either bacterial or viral or parasitic could affect dramatically rabbit industry causing great economic losses. One of the most familiar parasitic diseases of rabbit is the hepatic coccidiosis which causes high mortalities in young rabbit's especially among the age between 4-8 weeks. Hepatic coccidiosis caused by Eimeria stiedae occurred in the liver which is the vital organ for protein synthesis and storage of most of nutritive body material. The prevalence of coccidiosis in young rabbits (weaning up to 2 months old) was 95 to $100 \%$. Adult female rabbits usually acted as carriers within the farm and transmitted the parasite to young rabbits

\footnotetext{
* Corresponding author. Tel.: +202 3424406;

Fax: +202 3428321

E-mail address: svri@idsc.gov.eg

(M. S. El-Nabarawy)
}

which caused severe infection with clinical sings and even death (Wang and Tsai, 1991).

Economic losses from coccidiosis which reaches 75.8\% mortalities (Haiba et al.,1955), while (Arnoni 1978) showed that $48 \%$ of rabbit died on breeding farms of Pelotas, Weight loss and low food conversion as well as increased susceptibility to food after bacterial and viral disease.

Pasteurellosis remains a common disease in commercially produced rabbits (Digiacomo et al., 1983). Attention should be drawn to the fact that Pasteurella multocida is normal inhabitant of the upper respiratory tract of rabbits (Hippe, 1982) and when animals are subjected to stress factors the organism may provoke the disease.

Pasteurella multocida vaccines were moderately successful in protection against pasteurellosis in rabbits (Okerman and Spanoghe, 1981).

So this study was carried out to investigate the effect of coccidial infectation on the immune response of rabbits vaccinated with oil adjuvant pasteurella multocida vaccine.

\section{Materials and methods}

Bacterial strains. Vaccinal $P$. multocida serotype A and D are routinely used in the production of inactivated oil adjuvant polyvalent 
rabbit pasteurellosis vaccine obtained from Veterinary Serum and Vaccine Research Institute, Abbasia, Cairo, Egypt

Isolation and sporulation of Eimeria stiedae oocysts. This step was carried out according to (Abd El- Rahman, 1988), where Eimeria stiedae sporulated oocysts was provided and characterized by Deptartment of Parasitology, Veterinary Serum and Vaccine Research Institute, Abbasia, Cairo, Egypt. The obtained oocysts were washed with normal saline to remove the bile then transferred to a clean sterile Petri-dish containing $2.5 \%$ potassium dichromate solution for a depth of 3-5 $\mathrm{mm}$ and incubated at $26^{\circ} \mathrm{C}$ with a relative humidity $76-80 \%$. Sporulation of the oocysts was followed up daily until complete sporulation was obtained, the contents of the Petri- dish were centrifuged at $3000 \mathrm{rpm}$ for 1.5 minutes where the supernatant was discarded and the sediment was washed several times with distilled water and recentrifuged as before until the supernatant become clear. The sediment was re-suspended in $2.5 \%$ potassium dichromate solution and stored at $40^{\circ} \mathrm{C}$ until used.

Propagation of Eimeria stiedae. It was carried out according to Zhang et al., (1996) where 10 rabbits of one month old free from Eimeria were infected with 30000 freshly sporulated oocysts of Eimeria stiedae, rabbit inoculated per os (Ragab, 2001) then the oocysts were collected from the gall bladder of slaughtered rabbits 1week post infectation and sporulated as mentioned above.

Storage of sporulated oocysts. Sporulated

Table (1): Experimental schedule.
Eimeria stiedae oocysts were stored in 2.5\% potassium dichromate solution at $4{ }^{\circ} \mathrm{C}$ as mentioned (Abu El-Ezz, 1994).

Anti coccidial drug. Aviax 5\% (semdurmycin 150) was supplied by (Phibro) and used through mix of $500 \mathrm{gm} / 1000 \mathrm{~kg}$ of finished feed to provide $25 \mathrm{ppm}$ of semduramycin up to 5 days.

Rabbits. A total of 60 New Zealand rabbits were used (4 to 8 weeks old and about $1.5 \mathrm{~kg}$ body weight). These rabbits were chosen from flocks with neither history of Pasteurellosis nor vaccinated against the Pasteurella multocida. No antibodies to Pasteurella multocida were detected in blood sample. Nasal swabs from the rabbits were cultured on blood agar and proved to be negative for Pasteurella multocida. Rabbits were grouped and vaccinated as shown in Table (1).

Samples. Fecal samples were collected and examined by using flotation technique from $5^{\text {th }}$ day till the third week post infection. Also oocysts count was carried out using McMaster technique. Also blood sample were collected from the ear vein before vaccination, after the first and second dose of vaccination, then every two weeks till the end of experiment from each groups. Sera were separated and stored at $-20^{\circ} \mathrm{C}$ till used.

Indirect heamagglutination test (IHA). It was done according to Carter and Rappay, (1962).

Enzyme linked immunosorbent assay (ELISA). It was carried out according to Briggs and Skeels, (1984).

\begin{tabular}{|c|c|c|c|c|c|c|}
\hline $\begin{array}{l}\text { Animal } \\
\text { group }\end{array}$ & Subgroups & $\begin{array}{c}\text { No of } \\
\text { rabbits }\end{array}$ & $\begin{array}{l}\text { Vaccinated } \\
\text { group }\end{array}$ & Infested group & Treatment $^{1}$ & Challenge \\
\hline \multirow{2}{*}{ A } & A1 & 6 & \multirow{9}{*}{$\begin{array}{l}1 \mathrm{ml} \text { containing } \\
10^{9} \mathrm{CFU} \mathrm{P} \text {. } \\
\text { multocida } \mathrm{S} / \mathrm{C} \\
\text { at } 4 \text { weeks }\left(1^{\text {st }}\right. \\
\text { dose }) \text { then at } 8 \\
\text { weeks }\left(2^{\text {nd }} \text { dose }\right.\end{array}$} & Infested at time of the $1^{\text {st }}$ & Treated & $0.2 \mathrm{ml} \mathrm{S} / \mathrm{C} \times 10$ \\
\hline & $\mathrm{A} 2$ & 6 & & dose of vaccine & Non & LD50 diluted \\
\hline \multirow{2}{*}{ B } & B1 & 6 & & Infested after 15 days from & Treated & from \\
\hline & B2 & 6 & & $1^{\text {st }}$ dose of vaccine & Non & concentration \\
\hline \multirow{2}{*}{$\mathbf{C}$} & $\mathrm{C} 1$ & 6 & & Infested at time of the $2^{\text {nd }}$ & Treated & of $10^{9} \mathrm{CFU}$ of \\
\hline & $\mathrm{C} 2$ & 6 & & dose of vaccine & Non & P. $\quad$ multocida \\
\hline \multirow[b]{2}{*}{ D } & D1 & 6 & & Infested after 15 days from & Treated & cell suspension \\
\hline & $\mathrm{D} 2$ & 6 & & $2^{\text {nd }}$ dose of vaccine & Non & after 2 weeks \\
\hline $\mathbf{E}$ & & 6 & & Non & Non & from $2^{\text {nd }}$ dose \\
\hline $\mathbf{F}$ & & 6 & Non & Non & Non & of vaccine \\
\hline
\end{tabular}

1 Treatment with Aviax $5 \%$ (semduramycin) after 2 days from infestation with Eimeria stiedae.

\section{Results and Discussion}

Hepatic coccidiosis of rabbits has been investigated by many authors. This parasitic infection remains one of the most important disease problems in young rabbits than the growing ones because the susceptibility to infection in young rabbits is very high. This picture might be attributed to lack of immunity among young individuals, while it was gradually established among the growing mates (Calnek et al., 1997).

Many immunological studies were carried out in the control of coccidiosis, several points need excessive investigation particularly those 
Table (2): Effect of E. stiedae infectation and treatment on immunized rabbits with oil adjuvant Pasteurella multocida vaccine (against type A) using indirect haemagglutination test.

\begin{tabular}{ccccccccc}
\hline \multirow{2}{*}{$\begin{array}{c}\text { Animal } \\
\text { group }\end{array}$} & Subgroups & Pre-vaccination & \multicolumn{5}{c}{ Weeks Post $\mathbf{1}^{\text {st }}$ dose of Vaccination } \\
\cline { 4 - 8 } & & 12 & 2 & $\mathbf{4}$ & $\mathbf{6}$ & $\mathbf{8}$ & $\mathbf{1 0}$ & $\mathbf{1 2}$ \\
\hline A & A1 & 12 & 66 & 301 & 670 & 912 & 1609 & 1990 \\
& A2 & 11 & 289 & 326 & 663 & 905 & 1512 & 1995 \\
B & B1 & 11 & 295 & 118 & 345 & 560 & 998 & 1349 \\
& B2 & 10 & 284 & 463 & 675 & 922 & 1614 & 2016 \\
C & C1 & 10 & 287 & 460 & 450 & 658 & 1060 & 1412 \\
& C2 & 11 & 289 & 450 & 885 & 952 & 1649 & 1971 \\
D & D1 & 11 & 290 & 456 & 889 & 495 & 970 & 1340 \\
E & D2 & 12 & 294 & 464 & 891 & 1197 & 2018 & 2521 \\
F (Control) & & 11 & 11 & 12 & 13 & 13 & 12 & 10 \\
\hline
\end{tabular}

Group (A1): Infected with the $1^{\text {st }}$ dose of vaccine and treated.

Group (A2): Infected with the $1^{\text {st }}$ dose of vaccine but did not receive treatment.

Group (B1): Infected at 2 weeks after $1^{\text {st }}$ dose of vaccine and treated.

Group (B2): Infected at 2 weeks after $1^{\text {st }}$ dose of vaccine but did not receive treatment.

Group (C1): Infected at the time of $2^{\text {nd }}$ dose of vaccine and treated.

Group (C2): Infected at the time of $2^{\text {nd }}$ dose of vaccine but did not receive treatment.

Group (D1): Infected after 2 weeks from $2^{\text {nd }}$ dose of vaccine and treated.

Group (D2): Infected after 2 weeks from $2^{\text {nd }}$ dose of vaccine but did not receive treatment.

Group (E): Vaccinated rabbits.

Group (F): Non vaccinated, non infected and non treated (control).

concerned with immunity and vaccination (Abdel Rahman, 1988).

Rabbit pasteurellosis and coccidiosis represents two major problems facing rabbit industry and may lead to complete destruction of a rabbit farm. So, the present work investigates the effect of rabbit coccidiosis and its treatment on the immune response of rabbit vaccinated with inactivated oil adjuvant haemorrhagic septicaemia vaccine. In a trial to answer the question about the administration of such vaccine to rabbits at the time of vaccination when such rabbits found to be infected with Eimeria stiedae or received a specific treatment as semduramycin 150 .

The experimental infection of rabbits with Eimeria stiedae (group A, B, C, D) revealed loss of appetite, diarrhoea and distension of abdomen which agree with that recorded by (Rosimin and Simoni, 1979). The daily faecal examination for Eimeria stiedae oocyst revealed gradual decrease in number of oocyst till complete disappearance after 9-11 days post infestation in groups (A1, B1, C1, D1) which treated with semduramycin, while faecal samples from groups (A2, B2, C2, D2) which did not received the drug treatment showed the presence of Eimeria oocysts from the $7^{\text {th }}$ day post infestation in $100 \%$ of rabbits till the $3^{\text {rd }}$ week post infestation.
The humoral immunity was estimated by indirect haemagglutination test and ELISA technique as shown in Tables $(2,3,4,5)$. Rabbits vaccinated and infected with oocysts of Eimeria stiedae either at the time or after 15 days from first or second vaccination (subgroups A1, B1, $\mathrm{C} 1, \mathrm{D} 1)$ and treated with semduramycin 150 showed slight decrease of the antibody titre against $\mathrm{P}$. multocida type $\mathrm{A}$ and $\mathrm{D}$ then elevated and reaching their peak at 12 weeks post the $1^{\text {st }}$ dose of vaccination. The above results revealed that the semduramycin ionphoric coccidostat plays an important role for protection of infested rabbits against coccidia and improved their immune status preventing failure of vaccination even when given at the time of vaccination. These results agreed with that of El-Schemy et al., (2009).

In subgroups (A2, B2, C2, D2) which were vaccinated and infected at the time or after 15 days from the first or second vaccination but not receive treatment showed sudden decrease of $P$. multocida antibody titres after infestation then increased slowly till the end of the experiment. These results agreed with Barriga and Anani (1979) who reported that E. stiedae destroys part of the liver of rabbits (which in turn disturb liver enzymes. Furthermore, serum protein and immunoglobulin were affected (Haiba and Geneidy, 1965, Awadalla and Hegazi, 1992). 
Table (3): Effect of E. stiedae infectation and treatment on immunized rabbits with oil adjuvant Pasteurella multocida vaccine (against type D) using indirect haemagglutination test.

\begin{tabular}{lcccccccc}
\hline \multirow{2}{*}{ Animal groups } & \multirow{2}{*}{ Subgroups } & \multirow{2}{*}{ Pre-vaccination } & \multicolumn{5}{c}{ Weeks Post $\mathbf{1}^{\text {st }}$ dose of Vaccination } \\
\cline { 4 - 8 } & $\mathrm{A} 1$ & 12 & $\mathbf{2}$ & $\mathbf{4}$ & $\mathbf{6}$ & $\mathbf{8}$ & $\mathbf{1 0}$ & $\mathbf{1 2}$ \\
\hline \multirow{2}{*}{$\mathbf{A}$} & $\mathrm{A} 2$ & 12 & 60 & 1298 & 675 & 915 & 1596 & 1990 \\
& $\mathrm{~B} 1$ & 11 & 288 & 330 & 649 & 585 & 1042 & 1360 \\
$\mathbf{B}$ & $\mathrm{B} 2$ & 11 & 280 & 113 & 336 & 544 & 991 & 1349 \\
& $\mathrm{C} 1$ & 10 & 289 & 455 & 662 & 910 & 1632 & 2016 \\
$\mathbf{C}$ & $\mathrm{C} 2$ & 10 & 275 & 461 & 446 & 645 & 1056 & 1412 \\
& $\mathrm{D} 1$ & 11 & 283 & 458 & 879 & 960 & 1540 & 1971 \\
D & $\mathrm{D} 2$ & 11 & 278 & 456 & 872 & 481 & 950 & 1340 \\
E & & 12 & 285 & 458 & 879 & 1198 & 2005 & 2521 \\
F (Control) & & 11 & 11 & 12 & 13 & 13 & 12 & 10 \\
\hline
\end{tabular}

Group (A1): Infected with the $1^{\text {st }}$ dose of vaccine and treated.

Group (A2): Infected with the $1^{\text {st }}$ dose of vaccine but did not receive treatment.

Group (B1): Infected at 2 weeks after $1^{\text {st }}$ dose of vaccine and treated.

Group (B2): Infected at 2 weeks after $1^{\text {st }}$ dose of vaccine but did not receive treatment.

Group (C1): Infected at the time of $2^{\text {nd }}$ dose of vaccine and treated.

Group (C2): Infected at the time of $2^{\text {nd }}$ dose of vaccine but did not receive treatment.

Group (D1): Infected after 2 weeks from $2^{\text {nd }}$ dose of vaccine and treated.

Group (D2): Infected after 2 weeks from $2^{\text {nd }}$ dose of vaccine but did not receive treatment.

Group (E): Vaccinated rabbits.

Group (F): Non vaccinated, non infected and non treated (control).

Table (4): Effect of E. stiedae infection and treatment on immunized rabbits with oil adjuvant Pasteurella multocida vaccine (against type A) using ELISA.

\begin{tabular}{|c|c|c|c|c|c|c|c|c|}
\hline \multirow{2}{*}{$\begin{array}{l}\text { Animal } \\
\text { groups }\end{array}$} & \multirow{2}{*}{ Subgroups } & \multirow{2}{*}{ Pre-vaccination } & \multicolumn{6}{|c|}{ Weeks Post $1^{\text {st }}$ dose Vaccination } \\
\hline & & & 2 & 4 & 6 & 8 & 10 & 12 \\
\hline \multirow{2}{*}{ A } & A1 & 90 & 705 & 1095 & 2270 & 3055 & 5309 & 6905 \\
\hline & A2 & 90 & 218 & 393 & 1230 & 1890 & 3259 & 4790 \\
\hline \multirow{2}{*}{ B } & B1 & 92 & 982 & 1070 & 2259 & 3060 & 5293 & 6900 \\
\hline & B2 & 91 & 995 & 381 & 1265 & 1960 & 3360 & 4758 \\
\hline \multirow{2}{*}{ C } & $\mathrm{C} 1$ & 95 & 985 & 1563 & 2290 & 3040 & 5213 & 6930 \\
\hline & $\mathrm{C} 2$ & 97 & 987 & 1569 & 1516 & 2171 & 3642 & 4769 \\
\hline \multirow{2}{*}{ D } & D1 & 93 & 885 & 1568 & 2998 & 3005 & 5305 & 6895 \\
\hline & D2 & 90 & 989 & 1578 & 3020 & 1680 & 3290 & 4689 \\
\hline $\mathbf{E}$ & & 89 & 998 & 1578 & 3029 & 4070 & 6861 & 8571 \\
\hline \multicolumn{2}{|c|}{ F (Control) } & 90 & 91 & 94 & 93 & 89 & 82 & 75 \\
\hline
\end{tabular}

Group (A1): Infected with the $1^{\text {st }}$ dose of vaccine and treated.

Group (A2): Infected with the $1^{\text {st }}$ dose of vaccine but did not receive treatment.

Group (B1): Infected at 2 weeks after $1^{\text {st }}$ dose of vaccine and treated.

Group (B2): Infected at 2 weeks after $1^{\text {st }}$ dose of vaccine but did not receive treatment.

Group (C1): Infected at the time of $2^{\text {nd }}$ dose of vaccine and treated.

Group (C2): Infected at the time of $2^{\text {nd }}$ dose of vaccine but did not receive treatment.

Group (D1): Infected after 2 weeks from $2^{\text {nd }}$ dose of vaccine and treated.

Group (D2): Infected after 2 weeks from $2^{\text {nd }}$ dose of vaccine but did not receive treatment.

Group (E): Vaccinated rabbits.

Group (F): Non vaccinated, non infected and non treated (control). 
Table (5): Effect of E. stiedae infection and treatment on immunized rabbits with oil adjuvant Pasteurella multocida vaccine (against type D) using ELISA test.

\begin{tabular}{ccccccccc}
\hline \multirow{2}{*}{ Animal group } & \multirow{2}{*}{ Subgroups } & \multirow{2}{*}{ Pre-vaccination } & \multicolumn{5}{c}{ Weeks Post 1 } & dose of Vaccination \\
\cline { 4 - 8 } & & & $\mathbf{2}$ & $\mathbf{4}$ & $\mathbf{6}$ & $\mathbf{8}$ & $\mathbf{1 0}$ & $\mathbf{1 2}$ \\
\hline \multirow{2}{*}{ A } & $\mathrm{A} 1$ & 90 & 695 & 1040 & 1996 & 3069 & 5314 & 6908 \\
& $\mathrm{~A} 2$ & 90 & 220 & 385 & 1195 & 1865 & 3240 & 4730 \\
B & $\mathrm{B} 1$ & 92 & 970 & 1030 & 2270 & 3065 & 5283 & 6890 \\
& $\mathrm{~B} 2$ & 91 & 980 & 365 & 1240 & 1920 & 3348 & 4748 \\
C & $\mathrm{C} 1$ & 95 & 975 & 1545 & 2287 & 3031 & 5275 & 6930 \\
& $\mathrm{C} 2$ & 97 & 983 & 1564 & 1502 & 2165 & 3609 & 4839 \\
D & $\mathrm{D} 1$ & 93 & 975 & 1575 & 2963 & 3009 & 5294 & 6899 \\
E & $\mathrm{D} 2$ & 89 & 973 & 1563 & 2997 & 1710 & 3260 & 4781 \\
F (Control) & & 89 & 985 & 1569 & 3019 & 4074 & 6852 & 8560 \\
\hline
\end{tabular}

Group (A1): Infected with the $1^{\text {st }}$ dose of vaccine and treated.

Group (A2): Infected with the $1^{\text {st }}$ dose of vaccine but did not receive treatment.

Group (B1): Infected at 2 weeks after $1^{\text {st }}$ dose of vaccine and treated.

Group (B2): Infected at 2 weeks after $1^{\text {st }}$ dose of vaccine but did not receive treatment

Group (C1): Infected at the time of $2^{\text {nd }}$ dose of vaccine and treated.

Group (C2): Infected at the time of $2^{\text {nd }}$ dose of vaccine but did not receive treatment

Group (D1): Infected after 2 weeks from $2^{\text {nd }}$ dose of vaccine and treated.

Group (D2): Infected after 2 weeks from $2^{\text {nd }}$ dose of vaccine but did not receive treatment.

Group (E): Vaccinated rabbits.

Group (F): Non vaccinated, non infected and non treated (control).

Table (6): Results of challenge test for evaluation of the protective efficacy of rabbit groups to $P$. multocida

\begin{tabular}{cccccc}
\hline Animal groups & Subgroups & No. of rabbit & No. of dead & No. of survived & Protection \% \\
\hline A & A1 & 6 & 1 & 5 & $83.4 \%$ \\
& A2 & 6 & 3 & 3 & $50 \%$ \\
B & B1 & 6 & 1 & 5 & $83.4 \%$ \\
& B2 & 6 & 3 & 3 & $50 \%$ \\
C & C1 & 6 & 1 & 5 & $83.4 \%$ \\
D 2 & D1 & 6 & 4 & 2 & $33.4 \%$ \\
D & & 6 & 4 & 2 & $83.4 \%$ \\
F (Control) & & 6 & 0 & 6 & $33.4 \%$ \\
\hline
\end{tabular}

Group (A1): Infected with the $1^{\text {st }}$ dose of vaccine and treated.

Group (A2): Infected with the $1^{\text {st }}$ dose of vaccine but did not receive treatment.

Group (B1): Infected at 2 weeks after $1^{\text {st }}$ dose of vaccine and treated.

Group (B2): Infected at 2 weeks after $1^{\text {st }}$ dose of vaccine but did not receive treatment.

Group (C1): Infected at the time of $2^{\text {nd }}$ dose of vaccine and treated.

Group (C2): Infected at the time of $2^{\text {nd }}$ dose of vaccine but did not receive treatment.

Group (D1): Infected after 2 weeks from $2^{\text {nd }}$ dose of vaccine and treated.

Group (D2): Infected after 2 weeks from $2^{\text {nd }}$ dose of vaccine but did not receive treatment.

Group (E): Vaccinated rabbits.

Group (F): Non vaccinated, non infected and non treated (control).

The results of vaccinated rabbits (group E) with oil adjuvant haemorrhagic septicaemia vaccine revealed a progressive and steady rise of antibody titre starting from the first week and thereafter post vaccination. These results were supported by Gergis (1993) and Lu et al., (1988). The obtained results in Table (6) revealed that challenge test of all rabbit groups with the virulent $P$. multocida gave a protective percentage of $83.4 \%, 50 \%, 100 \%, 0 \%$ in treated, untreated, vaccinated and unvaccinated rabbits respectively. While, the protective percents insubgroups $(\mathrm{C} 2, \mathrm{D} 2)$ were $33.4 \%$. These results agreed with Gamal et al., (2006). This may be 
due to challenge concurrency post two weeks or at the time of infestation. From the obtained results, it could be concluded that the important recommendation to rabbit owners to avoid coccidian infestation during vaccination programs, which act as a stress factor and failure of the vaccine.

\section{References}

Abdel Rahman, S.M. (1988): Studies on endoparasites of rabbit in Assiut. M.V.Sc. Thesis, Parasitology, Fac. Vet. Med., Assiut Univ., Assuit, Egypt.

Abu El-Ezz, N.A.T. (1994): Immunological studies on Eimeria species in fowls. Ph.D. Thesis, Parasitology, Fac. Vet. Med., Cairo Univ., Giza, Egypt.

Arnoni, J.V. (1978): Prevalence aspectos patologicos da coccidioso hepatic emoryctolagus cuniculus domesticus em pelotas, R.S. Master the Sis, Federal University of Rio Grande de Sul Porto Alegre, Rio Grand do Sul, Brazil.

Awadalla, S. and Hegazi, S. (1992): Influence of coccidiosis on liver and kidney functions in rabbits. Proc. $2^{\text {nd }}$ Cong., Fac. Vet. Med., Cairo Univ.,Giza, Egypt

Barriga, O.O. and Anani, J.V. (1979): Eimeria steidae weight gain, oocyst output and hepatic function of rabbits orcytalagus cuniculus with graded infection. Exp. Parasitol., 48 (3): 407-414.

Briggs, D.J. and Skeels, J.K. (1984): An enzyme linked immunosorbent assay for detecting antibodies to $P$. multocida in chickens. Avian Dis., 28 (1): 208-215.

Calnek, B.W.; Rornes, H.J.; Beard, C.W.; Medongeld, L.R. and Saif, Y.M. (1997): Diseases of poultry. Iowa State University Press, Ames, Iowa, USA, pp. 865-883.

Carter, G.R. and Rappay, D.E. (1962): Formalized erythrocytes in the haemagglutination test for Pasteurella multocida. Br. Vet. J., 118: 289-292.

Digiacomo, R.F.; Carling House, L.E. and Van Hossier, G.L. (1983): Natural history of infection with Pasteurella multocida in rabbits. J. Am. Vet. Med. Assoc., 183: 11721175.

El-Schemy, M.M.; Hussein, A.S.; Kamal, N.A. and Eskander, N.B. (2009): The effect of some anti-coccidial drugs on the immune response of rabbits experimentally infected with Eimeria stiedae and vaccinated with enterotoxaemia and bloat vaccine. Egypt. Vet. Med. Soc. Parasitol., 5-12.

Gamal El-Din, H.Y.; El-Khatib, R.M.; Kamal, N.A. and Khodeir, M.H. (2006): Effect of coccidiosis and treatment on the immune response of rabbit inactivated rabbit haemorrhagic virus vaccine. The $4^{\text {th }}$ Sci. Cong., Minufiya Vet. J., 4 (2): 381-387.

Gergis, S.M. (1993): Pneumonia in domestic rabbits in Egypt. Strain types and methods of control. Cah. Options Mediterr, 8: 509-524.

Haiba, M.H. and Geneidy, A.I. (1965): Electrophorectic patterns of serum protein in normal and Ascaridia galli infested Egyptian chickens. J. Arab. Vet. Med. Assoc., 25: $39-49$.

Haiba, M.H.; Fahmy, M.A.M.; Abdou, A.H. and Selim, M.K. (1955): Survey on the incidence of parasites in farm animals of the Faculty of Veterinary Medicine, Cairo Univ., Agri. J., 11 (2): 181-186.

Hippe, W. (1982): Aetiological importance of pasteurella and bordetella in rabbit snuffles. Tierarztliche Umschau, 37: 284-290.

Lu, Y.S.; Afendis, S.J. and Pakes, S.P. (1988): Identification of immunogenic outer membrane protein of Pasteurella multocida 3:A in rabbits. Infect. Immun., 56 (6): 1532-1537.

Okerman, L. and Spanoghe (1981): Effect of inactivated pasteurella vaccines in specific pathogen free rabbits. Comp. Humoral Microbiol. Infect. Dis., 223-228.

Ragab, M. H. M. (2001): Vaccination trials against Eimeria stiedae in rabbits. Ph.D. Thesis, Parasitology, Fac. Vet. Med., Alexandria Univ., Alexandria, Egypt.

Rosimin, R. and Simoni, P. (1979): Histological and ultrastructural features of hepatic coccidiosis in rabbits. Revista Diconiglicatura, 16 (12): 31-36.

Sandford, J.C. (1986): The domestic rabbits. $4^{\text {th }}$ Edition, Collins, London.

Wang, J.S. and Tsai, S.F. (1991): Prevalence and pathological study on rabbit hepatic coccidiosis in Taiwan. Proc. Natl. Sci. Life Sci., 15 (4): 240-243.

Zhang, J.; Wilson, E.; Yan, S. and Healey, M.C. (1996): Increasing the yield of Eimeria tenella oocysts in primary chicken kidney cells. Avian Dis., 40: 63-67.

\footnotetext{
تأثير الإصابة بالكوكسيديا استيدى على استجابة الارانب المناعية للقاح التسمم الدموى الأرنبى الزيتى متعدد العترات

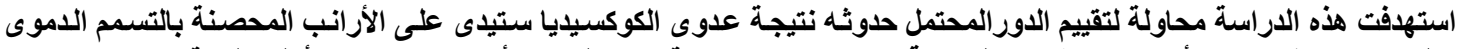

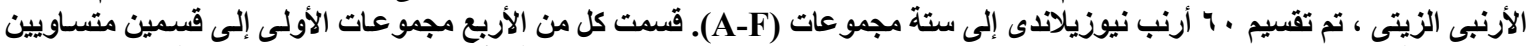

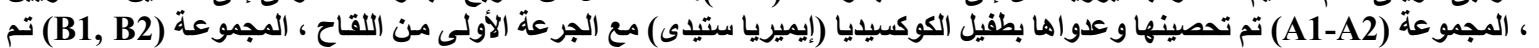

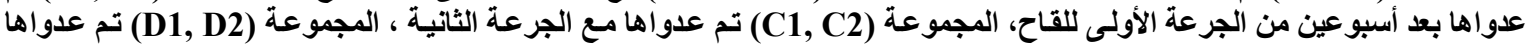

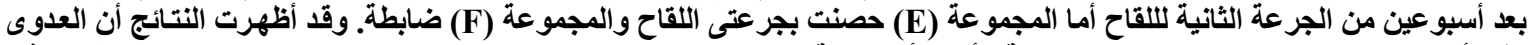

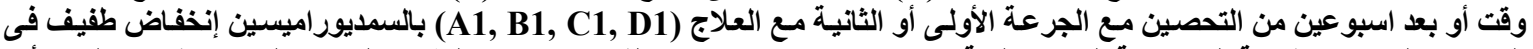

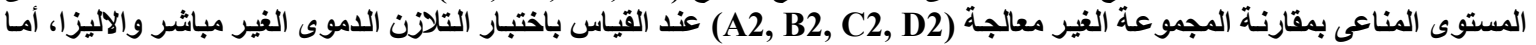

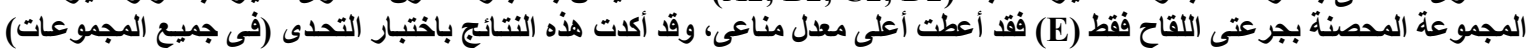

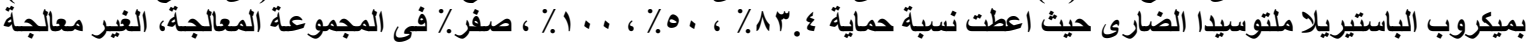

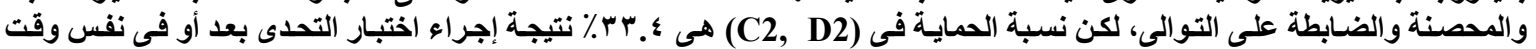

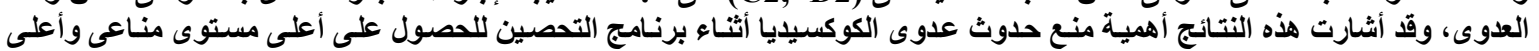
نسبة حماية للقاح التسمم الأرانبى الزيتى.
} 